\title{
Early Childhood: Motivation and Stress
}

\author{
Kelsey Verie Brown, Barba Aldis Patton \\ University of Houston-Victoria, USA
}

\begin{abstract}
Unfortunately stress is part of the everyday life. However it is especially sad when it is a part of the lives' of many young children. This stress is often so burdensome to children that they find it difficult to meet their many required tasks whether they are of academic in nature and just daily routine. The authors address the needs of many children from both theoretical and from personal communications with teachers who are in the classroom on a daily bases with children. Many of the factors which seem to be the roots of the problems have been uncovered in this work as well as the effect these have on the children.
\end{abstract}

\section{Introduction}

Stress as defined by Humphrey [1] can be considered as any factor, acting internally or externally that makes it difficult to adapt and that indicates increased effort on the part of the individual to maintain a state of equilibrium between him or her and the external environment. A few types of stress include physical, physiological, and social stress. Stress can also be categorized as positive, tolerable, and toxic. Examples of precipitants of a positive stress response in young children include dealing with frustration, getting an immunization, and the anxiety associated with the first day at a childcare center [2] These examples all help and protect the child, although at the moment the child may be frightened and stressed. The stress may be temporary but the positive effects of the stressor outlast the negative. As such, they provide important opportunities to observe, learn, and practice healthy, adaptive responses to adverse experiences [2]. The second stress response is a tolerable stress response.

Tolerable stress differs from positive stress because the stressful experiences present a greater threat to the child's well-being. According to Shonkoff and others [2] such experiences may include death of a family member, illness, parental divorce, natural disaster, or an act of terrorism. When these stressors occur it is typical of a parent to protect the child from harm and long-term consequences, which limits the child's knowledge of the stressor. Therefore, a vital characteristic of tolerable stress is how the parent helps the child cope, adapt, and control their stress response to the experience. Lastly, toxic stress can result from strong, recurrent, or continued activation of the body's stress response. Stressors that are capable of inducing a toxic stress response include child abuse, guardian substance abuse, familial violence, and family financial burdens. During toxic stress experiences parents cannot easily protect the child from the lasting effects. Toxic stress can have damaging effects on learning, behavior, and health across the lifespan [3]. Teachers play a key part in the life of children. It would be extremely beneficial if a teacher could offer help to relieve the stress of their students.

Childhood stress can be the result of many sources including hectic schedules, new experiences, world's news, and the stress experienced by their parents. This is just a short list of possible stressors because every person may react differently; a stressor to one child may not be a stressor for another child. Children may also experience stress from life changing experiences such as, death of a family member, divorce of parents, remarriage of a parent, birth of a sibling, or a parent's loss of job [4]. Although life-changing experiences are more dramatic than daily stressors, daily stressors may have a greater effect.

Staring at a young age, children are involved in many activities such as, sports, 4-H clubs, church groups, and choir. Their lives are constantly being scheduled with no time to socialize with friends or enjoy other activities they would like to participate in. With the child constantly involved and busy, they may experience stress from the lack of rest time. Without the down time the child may become mentally and physically fatigued, causing stress, anxiety, depression, and even sleep deprivation [5]. Some parents may place a large amount of pressure 
on the child to excel not only in school but also in their extracurricular activities. This type of stress can cause the student to focus on the need to be perfect and constantly stress about succeeding. When they fail to succeed, the child may feel stressed or anxious because they have failed to meet their guardian's expectations. Most children want to please their parents, so failing to do so is catastrophic in their eyes. It is possible that they feel as if their parents will not accept them or love them as much.

If a child's life is overscheduled and their time is consumed, they no longer have time to play with friends. Playing with their friends is activity that many children enjoy and need. Children may also lose time to hangout and relax with immediate and extended family members. The moments a child gets to spend with friends and family can serve as not only a time to relax but also a time to learn values and lessons [6]. Children also lose the chance to play in a natural and creative way. When students play in a natural manner they are able to explore different activities and choose what they enjoy and do not enjoy. Finding activities that they enjoy can bring joy and satisfaction to a child's life, instead of adding harmful stress.

Stress stemming from home can also affect children. At-risk populations are more likely to have children who suffer from stress. At-risk populations include financial strain, poor housing quality, neighborhood violence, food insecurity [7]. All of which can threaten the well-being of a child. When I child feels threatened this can cause major stress. Children tend to look towards their parents for safety, when they feel as if their parents are stressed and in danger. As adults they are responsible for finances, their own health, along with family members' health, their own parents' death, and work related stress. Children look up to their parents for safety and stability; if this safety net seems to be faulty the child will worry. If children see their parents worrying they seem to pick up on their anxieties. If mother or father displays little or no distress in response to a stressor, a child may perceive the event as relatively benign. If a parent displays symptoms of depression, anxiety, or other signs of psychological upset in association with a stressor, however, this may convey a high degree of threat to a youngster [8]. Consider families living in poverty as an example. Studies show that parents' depression and anxiety about financial problems increase their punitiveness unresponsiveness, and harshness toward their children; in two-parent families, they are more likely to have marital conflict. [9].

Children not only react to the stress of their parents but also world news. Disturbing images of war and natural disasters are played out on the television where children may see the news. This news can be terrifying to children because they do not know what is happening or who is in danger. Every few years a new "end of the world" story arises. Through television and social media these stories go viral and are ultimately are heard by children. Much of the world news that stresses children threatens their well-being and safety. Most of the time the child is scared that the stressor will end in death and the idea of death can frighten the child to the point of severe stress. If the child has not been educated on the matter of death, this can be frightening to them. Adding on to the stress and anxieties the children are experiencing. An example of stress through world news can be seen through weather news in South Texas. When teachers are informed of local tornado threat, the teacher will try their best to keep the information from the children while insuring the students' safety [10]. While the students are left in the dark, the classroom will remain calm but once the students hear the news of a tornado threat, chaos will begin. Many students will become scared, resulting in crying and questions of where parents are. Once the chaos has begun it is difficult for the teacher to gain their attention to focus on schoolwork and maintain a calm classroom environment. The last thing an educator wants is for their students to be scared and stressed while at school.

Many students may also suffer from sensory overstimulation. Children who suffer sensory overstimulation usually have a difficult time staying still and maintaining focus. This can be diagnosed too swift and the child could be labeled as having ADD, ADHD, and a child with bad behavior. This is not always the case; the child might simply have an issue with paying attention. If the teacher was able to help keep the children moving and active, it may help with the issue. By simply labeling the student, it can add stress to the child. Stress for not feeling adequate or smart enough for school, unable to please the teacher, and being considered an outcast. The child may now believe that they have an issue and are not "normal". Instead they should be taught that there are ways to deal with their hyper activity. The child may also believe they are not good enough and do not belong in school. If they feel rejected it is possible they will soon reject school and education. A simple avenue to prevent stress from arising with hyperactive students could be the implementation of stress balls or anything that will allow the child to fidget or be active at their desk [11].

When focusing on early childhood children they may experience different experiences that cause stress in their lives. Early childhood students may also struggle with trying new activities introduced to 
them at head start or pre-kindergarten. If a child is already timid and shy, they may experience stress of trying new activities such as eating new foods, playing with more than one friend at a time, learning to write their name, having to sit for a period of time, and trying new food.

Stress can be brought on by new experiences. Treading out into unknown territory can be terrifying for everyone. New experiences such as beginning head start, attending a new school, joining a new club or sports group can add stress to the child's life. they are suddenly thrust into a new environment, surrounded by new peers and new adult authority figures [12]. The future is unknown, but most people would like to know what is coming their way. Knowing the future is impossible, causing some to worry.

A major aspect of early childhood learning is peer interaction. Many children have thus far played with fewer playmates than the number of children in their classroom. Some early childhood children may be an only child. It is also possible that the siblings they do have are at school while they were at home, leaving the child with no playmates at home. Sharing belongings and positive group play can be a new struggle for the children [13]. In a social setting the toys are no longer one single student's property instead children must play together. By playing together it may not be possible for students to have a toy to themselves. In this situation, it is possible that several of the students may not understand the act of sharing because it was not needed at home with their own toys and games. In a school setting children must learn how to take turns; understanding that they must wait for a turn and allow others to play with the toy. As a result, learning how to share and realizing why they must share can bring stress upon the child [13]. Young children tend to express their stress through emotional responses such as crying, yelling, and throwing tantrums. In many instances playtime with peers turns into a catastrophe. For example, a 3year-old girl at a head start find it difficult sharing with others. The problem with sharing is not only with toys she is playing with at the moment but also with toys that she played with before and left out. At this point she is staking claim to all the toys, and they are all off limits to anyone except herself. When a child does play with a toy she has chosen for herself, she begins to scream and cry. When the teacher confronts her, the teacher cannot understand the girl because of her crying. These tantrums last a while, disrupt the classroom, and draw most of the teacher's attention away from the class. This example proves that the newly introduced act of sharing can be highly stressful for children [8].
Many early childhood aged children are attending school for the first time. Before then, they had spent the entire day with a family member or babysitter. For numerous children this the first task of enforced separation [1]. Head start or pre-kindergarten is the first time they will be with adults and children they have not met before. While at home the child is surrounded by family members they are comfortable with which implies there are typically few strangers. When entering school for the first time children are left with complete strangers, but many are not emotionally mature enough to understand they are safe at school. Many of the children fear being away from their parents; as a result, a constant question posed is "when is my mom coming?" At this age they are unable to understand what is happening and believe they have been left there and nobody will come to get them. For children who do not have a developed sense of continuity, this type of stress can be disastrous. As a result of this stressor, a child may react by throwing temper tantrums, crying, and screaming. On some occasions a student will complain of a stomachache or other ailment, in order to be united with their mother or father again [8]. Teachers should aim to ease this stressful transition. In order to ease the transition, the teacher must assure the parent that the child is safe and well taken care of. By doing so the parent can help with the child's transition at home as well. The teacher can also help by involving the child in fun and busy activities that will keep their mind off the absence of their parents [14].

Another stressful aspect of head start or prekindergarten is the enormous amount of new experiences. Most of the experiences children have been through up to this age are restricted to their home life or are highly monitored by their parents. They have yet to be introduced to new experiences outside the comfort of their home routine. The adults they are introduced to are typically friends of their parents and the children they play with are more than likely the children of their parent's friends. Children learn that they can trust whom their parents have chosen. Unlike at home, at school their parents are not present to help guide the child to the accurate friendships. An example of this occurred recently at a local head start. A 3-year-old boy refuses to eat any new foods as a result of his parents feeding him a diet extremely high in sugar. Instead of monitoring their child's meals, they have allowed him to eat whatever he chooses in order to avoid a tantrum from the child. As a result, his body is used to one type of food and any other type of food makes him scared. Not only that but more than likely the new food does not taste as sweet and appetizing as the sugary food he is used to [14]. The boy refuses to eat breakfast or lunch, and 
can go all day without eating. On rare occasion he will try a small bite of a new food but forces himself to throw up once he has tasted it. Once it is time to nap the student cannot sleep because he is hungry from not eating all day. Thus the child is making the refusal to eat a domino effect into additional stressful situations. Lastly, familial changes can bring stress upon children. It is possible that at some point a child will experience a parental divorce, death of a parent or relative, new relationship of a parent, or the birth of a sibling. Many children of divorce have transitory symptoms, which may take the form of excessive worrying, sadness, anger, oppositional behavior, impaired social relationships, and compromised school performance [15]. All of these factors can alter the child's home life and may stress the child.

About $25 \%$ of children in the US live with only one parent [16]. Most of which could be the result of a divorce. Children may be battered and injured by factors that are directly or indirectly associated with the divorce: reduced parenting time with one or both parents; financial instability; relocation, which involves changing schools and losing friends; and the inconvenience of traveling between the parents' homes [15]. At such a young age children cannot fully comprehend these changes and the stress that accompanies divorce. In the beginning of the parental split the children may experience excessive worrying, sadness, anger, difficult social relationships, and impaired school performance. This can be a result of the new adjustment in the child's life. Additional stress is added to the child's life when the parents move into separate homes. The child must strive to maintain a relationship with both parents at different times. Along with two separate houses comes split holidays and school breaks. Instead of being able to spend holidays with everyone together, the child has to split time and certain days with each parent and the families of each parent.

A child can also experience stress from the death of a parent or family member. Children may not understand what death is or where their family member has gone [17]. Being young, children also are unaware of how to grieve or comprehend their emotions. For a child confusion and fear is greater than the sadness of the loss. The stress of a loss will not last for a short period of time instead it will be prolonged. Stress of the death will never be fully relieved but others can help the child cope.

If a child is the first-born child, they may experience stress from the arrival of a sibling. Children who already have siblings may also experience stress from the birth of a sibling. Countless children can sense when their mother is pregnant but if they do not sense it, the child will know from their parents informing them. This can spark a sibling rivalry even before the baby has arrived. A child may begin to show more aggression in school and at home in order to become the center of attention. This can even happen to the most well behaved children, not only children who have behavioral issues. Often a child will begin to act like a baby in order to gain the affection of their parents. The child may go so far as to ask to be held like a baby but for pregnant mothers this may be difficult. If they have a close connection to their mother, the child might cling to their mother and seem tremendously needy. The child may feel as if all the attention they receive will be taken away and given to the new baby [18]. When the baby arrives the actions of the child may return to normal but the stress can alter their actions before and after the birth.

\section{Effects of stress}

When a person, child or adult, experiences toxic stress this stress may affect their health in numerous ways. With stress present in a person's life they may see changes in their behavior, moods, and body. Reactions to stress can include physiological reactions and behavioral reactions. Physiological reactions prepare the body to deal with the stress in the present and future. Chronic and persistent stress can cause physiological wear and tear to each system in the body [9]. A behavioral reaction is classified by anything the person does as a result of their stress. One can be considered more internalized than the latter.

Stressful events activate multiple biological systems, and thus chronic stress influences many aspects of physiological functioning [9]. Physiological reactions are uncontrollable reactions of the person's body during the stressor. In the moment physiological reactions are not the same for every person or every time stress arises. Some reactions include rapid heartbeat, perspiration, digestive issues, and high blood pressure.

During stressful moments, children may complain of stomachaches. This could be a result of the stress and it is termed nervous indigestion. Severe stress can cause the digestive system to pause or slow down. If the stress becomes chronic the child may develop digestive disorders such as nausea, diarrhea, and colitis [1], [19]. Not only can chronic stress cause digestive disorders; it can be a cause for digestive diseases.

Stress can also cause high blood pressure. Blood pressure is the force blood puts on the vessels walls as the heart pumps blood through the vessels. Pressure will always be present in the blood vessels but the pressure will be higher when the heart tightens and sends blood through the vessels. When a 
person is diagnosed with high blood pressure, their heart must pump harder to force blood through the arteries. This is a result of improper functioning of the heart and arteries. A possible result of high blood pressure is impaired blood flow to the entire body. If parts of the body are deprived of oxygenated blood, the tissue can become infected and even begin to die. The central nervous system can also be affected by high blood pressure. A potential effect on the central nervous system includes mild cognitive impairment and vascular dementia [19]. Ultimately causing problems with memory and speaking. The kidneys are also affected by high blood pressure. The kidneys filter waste products in the body, ridding the body of the waste. In order for the kidneys to rid the body of waste, they must be supplied with oxygenated blood. If a person suffers from high blood pressure, the kidneys will not receive the proper amount of oxygenated blood. After a prolonged lack of proper oxygen the kidneys can stop functioning, causing the need for dialysis. It is also possible that an aneurysm can occur. If this happens the kidneys can burst causing internal bleeding. [20]. A person's skeletal system can also be affected by high blood pressure [19]. Calcium helps maintain healthy bones. If the kidneys are not working properly they may rid the body of too much calcium. Without enough calcium bones can become weak and more prone to breaks. Stress can cause high blood pressure, which may not seem severe but can lead to severe outcomes.

When examining behavior reactions, there are three different types of behaviors. The three behavioral reactions connected to stress are, counter behavior, dysfunctional behavior, and overt behavior [1]. Counter behavior occurs when a child or an adult reacts to the stressor at the exact moment it is happening, such as taking relaxing deep breaths [1]. Secondly, dysfunctional behavior results in impaired or abnormal behavior [1]. This can be distinguished by an obvious mental block or inability to stay on task. Lastly, overt behavior involves body expression in order to alleviate the stress. Examples include facial expressions, biting of the lip, and pacing.

Stress can severely alter the behavior of children. Young children experiencing chronic stress also have poorer impulse control, more difficulty focusing their attention and thinking, and more trouble controlling their emotions, consistent with the effects of stress hormones on the prefrontal cortex and related brain areas [9]. Most teachers will say that a student who is not following rules, not paying attention or refusing to follow teacher instruction is a poor student but it could simply be a reaction to stress [14]. The reason some children have trouble paying attention in the classroom, remembering and following instructions, and focusing their thinking has more to do with the effects of stress than with their unwillingness to do what the teacher says.

Teachers also tend to have numerous students who battle anger issues or trouble controlling emotions. These anger issues cause fights, tantrums, and other unwanted actions while in school. A child's anger can cause a domino effect. Anger and tantrums can cause friends to isolate the student, disruption of family life, and possibly the refusal to excel in school. It is possible that a cause of the poor emotional control could be stress. Stress can be a trigger for angry behavior but it can also result from the anger of the child. An angry child is not likely to have many friends in school or outside of school. The child may experience stress from isolation as a direct result of their anger. If stress were a possible cause then it would benefit the teacher and student, if the teacher were able to find a way to help alleviate the stress of the student [21].

Although drug use may not occur during the early childhood stage, continued excessive stress can lead to eventual drug or alcohol abuse. Drug or alcohol abuse can also stem from the stress of having parents who are addicted to drugs or alcohol. An unstable and unsafe home life can become a major factor in the decision to use drugs. Although some may not persistently abuse drugs or alcohol, those who do are at risk for many issues. For the developing young adult, drug and alcohol abuse undermines motivation, interferes with cognitive processes, contributes to debilitating mood disorders, and increases risk of accidental injury or death [22]. When it pertains to school, children who partake in substance abuse are more likely to have low grades, high level of absents, and a higher risk of dropping out [23]. Drug abuse can also harm a person's physical health. Health related consequences include overdose, diseases and death [23]. When using drugs the risk of suicide, homicide, accidents, and illness significantly rise. When mixing drug use with stress, the outcome can be devastating. Along with physical health, mental health can be affected. Drug use can also make a person more susceptible for developmental lags, dispiritedness, retraction, and other mental issues [23]. Those who use drugs are also likely to have dysfunctional relationships with family and friends. Those closest to the drug user may disagree with the person's choices causing friction in the relationship. The rifts in the relationships can harm the drug user by taking away their home and support system. Children with a history of multiple stress experiences are more likely to drink or use drugs at a younger age, in order to cope with the stress. If the stress can be maintained, it may help stray the child away from drug or alcohol use and the consequences that accompany that. 
Their academic underachievement is associated with poorer cognitive stimulation at home, but it also seems to be related to the effects of stress on their developing brain functions and on memory, learning, language, and focused attention. All of which can negatively affect a child's ability to learn in the classroom. The reason some children have trouble paying attention in the classroom, remembering and following instructions, and focusing their thinking has more to do with the neurobiological effects of stress hormones than with their unwillingness to do what the teacher says. [9].

A physical danger can be excessive weight gain, which can cause a person to become overweight, obese, or morbidly obese. Stress can either result in two types of eating habits, overeating and under eating. For many people eating serves as an outlet for the stress, it is a way to cope with the negative. Roughly $30 \%$ of humans decrease food intake when stressed, whereas the majority of individuals increase their intake [24]. Stress induced eaters also do not choose food that is healthy. Stress-induced cortisol secretion influences food choices toward intake of highly palatable and energy dense, high-fat and sweet foods that provide relief from stress but may lead to weight gain [25]. Another possible way stress may affect person's weight is, stress may cause a decrease in physical activity. Balantekin and Roemmich [26] found that 8- to 12-year-old children were more likely to watch television than engage in physical activity following a stressor. Krebs, Himes, Jacobson, Nicklas, Guilday, Styne [27] defined overweight and obesity as follows: overweight is having excess body weight for a particular height from fat, muscle, bone, water, or a combination of these factors, and obesity is having excess body fat. The number of obese children between the ages of 219 years has reached approximately 12.7 million children [28]. With a rise in obesity numbers, comes a rise in health risk factors of obese youth. Obese youth are more likely to have risk factors for cardiovascular disease, such as high cholesterol or high blood pressure. In a population-based sample of 5- to 17-year-olds, $70 \%$ of obese youth had at least one risk factor for cardiovascular disease [29]. Obese adolescents are more likely to have prediabetes, a condition in which blood glucose levels indicate a high risk for development of diabetes [30]. In addition, children and adolescents who are obese are likely to be obese as adults [31]. This lends to the development for adult health problems such as heart disease, type 2 diabetes, stroke, and several types of cancer [32].

Children now face the threat of developing diabetes and high blood pressure; along with other life threatening conditions. Marcione [33] found that some obese children have arterial plaque similar to that found among 45 year-olds and other heart abnormalities that put them at an increased risk for heart disease. Such types of risk were not typical of children in the past; instead the general populations threatened by heart disease were older adults. The rise in obesity is not only a threat to specific health factors; it can threaten life expectancy. While the rise of health issues due to obesity rise, the age of the average life expectancy lowers. Today's children may have a lower life expectancy than their parents because of numerous health complications brought on by obesity [34]. Over the past century humans have managed to maintain a rise in the average life expectancy, until now. Instead of continuing to extend the average life expectancy, we have managed to lower the average age of life expectancy.

Lastly, chronic stress can lead to anxiety disorders and chronic symptoms that a partnered with anxiety disorders. An over stressed child can grow up to be an overly fearful adult, that can impact the daily life on an individual. Ongoing physical symptoms of stress can also affect a child's adult life. Physical symptoms can become a chronic problem the person will have to deal with because of the excess stress. Excessive sleep disturbances can also affect the child into adulthood if stress is chronic [35]. An inadequate amount of sleep can lead to a lower immune system, decrease in brain activity, and constant fatigue. Extreme fear and anxiety can also cause a person to withdraw from society and friendships, which serve as a healthy part of a person's life. To some stress may seem like a simple reaction to an event but it can lead to more. There are many behavioral, physical, and emotional reactions that can be temporary or prolonged.

\section{Motivation in the Classroom}

The term motivation is derived from the Latin verb movere (to move). The idea of movement is reflected in such commonsense ideas about motivation as something that gets us going, keeps us working, and helps us complete tasks [36]. Motivation cannot be seen but can be observed through a person's actions and words. One can tell if a person is motivated by seeing or hearing their passion and desire to reach a specific goal. Motivation involves progressing towards a personal goal. Obstacles and stress will usually burden the progress towards the goal but with the motivation it can be obtained. Often the obstacles will set a fire under the motivation of the person. [36].

Children and adults can be affected by both intrinsic and extrinsic motivation. Intrinsic motivation is defined as the doing of an activity for 
its inherent satisfactions rather than for some separable consequence [37]. With intrinsic motivation the person is motivated by the fun or challenge, rather than the external rewards. From birth onward, humans, in their healthiest states, are active, inquisitive, curious, and playful creatures, displaying a ubiquitous readiness to learn and explore, and they do not require extraneous incentives to do so [37]. Humans are born with a curious desire to learn and explore new experiences. This curiosity can serve as a natural intrinsic motivator. The basis for this curiosity is not the same for every individual, because people's personal interests vary.

As children age the power of intrinsically motivated tasks decreases and the switch is made to extrinsic motivation. Extrinsic motivation is a construct that pertains whenever an activity is done in order to attain some separable outcome [38]. Extrinsic motivation is motivation to perform and succeed in order to achieve a specific result.

An example of intrinsic motivation versus extrinsic motivation can be seen through classwork and grading. Students who are focused on receiving A's are extrinsically motivated by the grade they receive [39]. Those students who seem to embrace their work and enjoy learning more than the grade they receive are intrinsically motivated. Those intrinsically motivated care about the genuine gain of knowledge, while extrinsically motivated students' care about the grade rather than the gain of knowledge.

\section{Motivation methods}

Motivation, both intrinsic and extrinsic, plays a major role in education. Teachers play an important role in children's lives, especially in early childhood. Without their parents at school, children look to their teachers for guidance. Sadly, many students may have a lack of motivation from home. In this case the teachers become a main source for guidance and motivation. Students arrive at school with an already determined degree of motivation, but this can be affected by the teacher's actions. But the teacher's behavior and teaching style, the structure of the course, the nature of the assignments and informal interactions with students all have a large effect on student motivation [40].

Teachers serve as a key motivator in students' lives. As a result of the diversity of students, not all students are motivated the same. Teachers must strive to help find the motivation for individuals rather than groups. Experience and inexperienced teachers can both implement different methods of motivation in their classrooms [41].
One way of implementing the use of classroom motivation is setting up a positive classroom environment [39]. Students should feel free to express their personality and opinions in the proper manner. For many students' home life is not positive. Instead it is stressful. At such a young age many children may deal with poverty, foster care, parental drug use, abuse, neglect, and parental depression. According to Thompson and Haskins [9] in 2012, more than six million, or 22 percent, of US children under age six lived in poverty. The percentage of children under age six who live in poverty is the largest proportion of any age living in poverty. When living in poverty, there may be a lack of food, proper medical care, or safe housing, all of which can cause a child to worry. A second cause of stress and trauma is child placement in foster care. Nearly 120,000 children under age six entered foster care in 2012, with the highest proportion of them under age one [9]. These children are placed into new homes, with people they have never met before. This can bring on feelings of abandonment and loneliness inevitability causing a child to feel as if there is no place to feel welcomed and comfortable. Thompson and Haskins [9] also state that children one-year-old and younger account for 20 percent of substantiated abuse or neglect cases, and children under age six accounts for nearly half of all cases. Abuse can cause many issues with children. A child may become angry and lash out towards authority figures or other children. Rather than signs of anger, some children may become reserved and distant from others which could ultimately cause negative feelings towards attending school and participating in the learning process. In 2010, more than half the children living with their families in homeless shelters were under age six [9]. Children who do not have a permanent, stable home may have to worry about where they will sleep, what they will eat, and even where they will do their homework. There is a constant feeling of instability and worry. A child spends just as much time at school as they do at home. This makes the classroom environment crucial to a child. School may be the only place where they receive meals or loving attention from their teachers. If the school environment is also negative, the child has no place to feel safe. In a negative classroom environment, students may be scolded often, given few chances to speak, and frequent punishment. Many of the "bad" students need teachers to give the students a chance to succeed and chance to understand why the student chooses certain behavior. In a negative classroom environment the students are not encouraged to express themselves or their personal ideas, ultimately causing the children to become reserved and wary an action that can cause worrisome and stressed 
students, to be assured that school is not a place for them [41]. By preparing a positive classroom environment, the child feels safe in their surroundings and safe being themselves.

When students first enter the classroom, they should be given a sense of control [14]. Allowing the students to choose what activities to play, what books to read, and allow them to ask questions, helps connect the students' to school. With a greater connection to the information they are learning, there is possibly a greater motivation to learn. Their curiosity is sparked and once they are interested, the desire to learn is heightened. Also, allowing students to choose whom they play or learn with can help aid their motivation. By choosing their learning partner, they may embody a deeper desire to learn or succeed because they are learning with a friend. Time and time again, a teacher has chosen the student's partner. If the child is a not friends with the partner it can make classwork harder to complete in a timely manner. A second way of offering students some control of the classroom is assigning responsibilities [42]. Most children see a classroom job or responsibility as a privilege and want to ensure their job is done. They become motivated to complete their responsibility and in the end want to feel valued. Also, most of the students who come from a stressful home, may feel as if they can control their surroundings, something that may seem impossible at home. If students are in charge of aspects of the classroom, they may find a certain motivation to do well in school [43].

The interests and passions of a person can spark a majority of motivation. If a classroom is set up with only a few topics and activities, many students will not find something to enjoy during the year. For these students it is difficult to become motivated for something they do not find interesting [14]. If a teacher is able to mix up their lessons, this can catch the eye of each student and spark the individual motivations [42].

Teachers should try to learn about their students as individuals and the interests they have. With this knowledge of the students the teachers can plan lessons accordingly and strive to include the interests of most of the students. By involving students' interests, this could help spark the intrinsic motivation of students. It is also important that every student is given a chance to succeed. Teachers must pay attention to the academic strengths and weaknesses of their students. If a child feels as if they can excel, they may feel more motivated. Children like to feel valued and recognized in anything they do. Teachers must give them the chance by involving varied lessons that focus on the strengths of all students [41]. In order to succeed at the aforementioned, a teacher must strive to get to know their students. This does not mean simply knowing their first and last name; instead know who the student truly is. It is beneficial to learn the student's interests, dislikes, and their personalities. This can ease the teacher's motivation and teaching process.

A teacher should also set clear goals and objectives for students. If a child is unaware of the outcomes they need to produce, they may feel confused and insecure about their actions. If the teacher defines a clear goal, then the student feels secure in their educational journey. For example, a head start teacher decides to have the students complete a Christmas craft. If the teacher shows an example of the finished product and makes her objectives clear, the students can become motivated to mimic the teacher's craft [39]. If an example is never given to the students, then they are unaware of their objectives. If this is the case, then the students will become discouraged as a result of not knowing how to complete the task. In the end the student motivation is lost due to uncertainty. The teacher's goals for students should also be high but attainable. While teachers are pushing students to excel, the students will learn to push themselves as well. Seeing their results gives the confidence and assurance that they need to believe they can achieve higher goals [44]. If the students believe they can reach a certain goal they will strive to, but if it seems impossible, there is a chance they will just feel like giving up instead of trying causes a loss of motivation [42].

In order to keep students motivated it can be useful to change the scenery from time to time. Staying in a desk all day, in the same room can become mundane and boring which can cause the motivation and drive to diminish overtime. The body and brain become tired and lose the excitement for school. Recently the classroom has seen a rise in students who struggle with fidgeting, sitting still, and lack of focus. If the option of walking outside is given to the students, they may embody a motivation to work until it is time to go outside or do something different. Classroom teachers have found the movement breaks to be valuable because they break up the day and refresh everyone, including the teachers, who feel that the movement also relieves stress [45]. Besides a change of scenery to mix the routine up, a teacher can also incorporate fun activities in replace of certain mundane activities. For students who struggle with staying engaged, a fun game can help gain and maintain their attention. Not every activity needs to be fun, but involving a few games a week can motivate students to behave well and learn. Mixing up lessons by incorporating positive competition can also help motivate students to try harder and do well. Most children feel the need 
to win, so making learning a competition can help students' complete classwork while trying their best. Although it is a great motivational tactic, the teacher must strive to insure the competition is healthy. Without the chance to take a mental break the students make become burnt out and dislike the thought of classwork and learning.

Another way teachers can offer motivation in their classroom is to offer rewards and positive reinforcement. With the use of rewards, students may become more motivated to excel in school. Rewards can also feel like someone accepts and appreciates them when they receive rewards and reinforcement for their actions. An example of an extrinsic reward is throwing the students a pizza party if they all pass an important test. By doing so the students have a tangible goal with a reward they would love, causing their level of motivation to rise [14]. Children also look towards adults for praise and excitement. There will always be children in the class that do not receive praise of from their parents or guardians. They child may also not experience their parents excitement when it comes to the actions of the child. At that age children see excitement as a sign of achievement. A child typically feels as if they have succeeded and have made the right decision. Without an adults praise, the child may feel as if they have done the wrong thing. A result of lack of praise can result in lower confidence of the child. Lower confidence can cause a child to retract themselves from school and other activities [40]. If a teacher motivates a student by using rewards and praise, the child may find the desire to excel.

Many students deal with the anxiety that comes with struggling with schoolwork. Failure to do well can cause student frustration and bring down the student's confidence along with their motivation level. When teachers offer feedback, the child is receiving a second chance with extra knowledge. Feedback can also show the student where they went wrong and where they can improve. Students always need a chance to improve. Knowing that giving up is not an option can boost their motivation.

\section{Relieving Stress with Motivation}

Through Hofferth and Sandberg's [46] research, they identified that children 3 to 5 years old spend 12 hours a week at school, while children aged 6 to 8 years spend approximately 32 hours a week in school. While looking at those statistics it is obvious that children spend a large amount of time with their teachers. Teachers must take on many other job titles besides solely the teacher; some include referee, councilor, and role model. Most teachers feel the need and desire to protect their children, whether it is physical harm, anxiety, or fear.

For children a major issue is stress and having to deal with the symptoms that partner the stress. If asked why a person when into teaching, the usual answer is because of their love for children and wanting to help the children. Teachers do not want to see their students in distress; because of this teachers strive to alleviate the stress of their students [40]. One method that can be implemented to relieve the stress can be the use of motivation in the classroom. Methods of motivation have been described previously, but certain methods of motivation can be more helpful when trying to relieve the stress of students. The previously mentioned methods can also be examined throughout a child's school career from head start all the way through college. In this section the focus will be on relieving stress of early childhood students through motivation.

In this stage of a child's life many of the stressors are new to the child. Before school they will experience stress but not to the extent they will while attending school. The child must now deal with stress at home and the stress at school and for some children this can be a vast amount of stress. Teacher should strive to relieve some of the stress and help the child as much as possible [41]. An early childhood teacher should first try to understand the root of the stress and what is causing the issue. Once the issue has been determined, the teacher should evaluate a plan to battle the child's stress and ultimately teach the child how to manage their stress. After a year the student will move on to a new teacher and a new classroom. If the teacher is able to teach the child stress relief techniques, then the child can prosper in other classroom where the teacher is not present to help relieve the stress. Eventually a student should learn to spot their stress and finally try to find a solution. Before they can do that, a teacher must strive to relieve their stress as much as possible.

Before children begin to experience the stress that accompanies attending school, children have already experienced stress at home. Early childhood stress at home can be brought on by a large amount of causes. While at home it is possible that a child is experiences neglect and abuse at home from the parents or guardians. The neglect can be considered a lack of food, lack of sleep, and improper hygiene. First, a sleep-deprived person cannot focus attention optimally and therefore cannot learn efficiently [47]. Abuse can consist of physical, sexual, and verbal abuse. A second cause of stress from home can be a change in the familial structure, for example a remarriage, divorce, or birth of a new sibling.

If a child experiences neglect from either lack of food, lack of sleep, or improper hygiene a teacher can 
help this student by motivating them. When it pertains to lack of sleep and food, a teacher should insure the student that everyday no matter the circumstance the child will receive two meals, a snack, and a nap. The child will be motivated to stay positive because they know school will offer what their home environment is lacking. Although the stress will not be completely eliminated, the child will have a place where they know is safe and will provide. As for hygiene at the early childhood level, teachers can educate the students about how to wash their hands and brush their teeth. At this age many of the students rely on parents to maintain their hygiene. If the teacher is able to educate the child, the child can now take over their hygiene routine. At such a young age they might not be able to complete the task like an adult would but the child at least can try. Which in some cases is more than a guardian would do for them. As for child abuse, physical, verbal, or sexual, a teacher can provide a safe environment for the child. The teacher can also motivate the child to open up to other adults and form relationships are loving. Instead of being afraid of adults, the child should understand some people are loving. Motivating them to form healthy relationships can begin with teaching the child what a healthy relationship looks like. When a child walks into the classroom the teacher can show excitement for seeing the child and even hug the child so they feel comfortable and have some affection. Another stressor for a child is the birth of a new sibling. When a mother becomes pregnant the child can sense the change coming. It is typical for a child to want to cling to their mother and become extremely needy. In order to relieve this stress with motivation, the teacher can teach the child about baby's and how the child can help their mom take care of the new baby. Most children enjoy helping so they will become motivated to help and show their mom how they can care for their new sibling. Although a teacher cannot completely alleviate the stress that comes from the child's home, the teacher can educate the student on how to handle the stress.

For many children positive interaction with peers and adults in school can be difficult. Children may tend to lash out, throw tantrums, and shut down when an encounter does not go like they wish. For example, in a head start classroom, a 3-year-old girl who is playing with a specific toy throws a fit when a friend begins to play with her. She begins to yell and cry hysterically, causing a disruption in the teachers teaching and the students learning. As a result of the crying, the teacher is unable to understand the issue the child is facing. Unless the child can calm down, the screaming and crying will continue until the child gets their way. At this point the child has not only experienced stress but the teacher has also begun to stress over the child's poor peer interaction. At this age it is not uncommon for this reaction to peer interaction. For many, this is their first school experience; they simply are unaware how to react to situations. In order to lower the stress associated with peer and adult interactions, such as the one mentioned before, a teacher can help the student voice their problems [41]. The student can become motivated to use their words in order to obtain the desired outcome of the situation. A teacher can teach a child to talk to the other child or ask an adult for help, rather than screaming and yelling to the point that the tantrum is bigger than the initial issue. Urging students to use phrases such as, "I don't like that" or "We can play together". When a teachers ask students to tell them when there is a problem can also help alleviate the stress of peer interactions.

For many students the motivation to receive a certain reward can help alleviate their stress [43]. Previously mentioned, a student struggled with eating at school as a result of only eating sweets at home. This caused the child to refuse both breakfast and lunch, but he did enjoy the snack before leaving to go home. In order to convince to the student to eat breakfast and lunch the teacher may offer a sweet snack at the end of the day. The sweet snack can motivate the student to eat the meals they may refuse to eat at first. This insures that the student is receiving a meal and the nutrients that the meal offers. Prior to the motivation to try new food, the child had no idea what the new food tasted like. It is possible that the child may like the new food and begin to eat nutritious meals regularly.

A major aspect of a head start classroom is the introduction of vast amount of new information [14]. This is a child's first educational experience; because it is their first the information may be brand new and unheard of before. The children will learn colors, numbers, months of the year, and days of the week, just to name a few. The introduction of new information may overwhelm the child and make them extremely tired and stressed. In order to relieve the stress a teacher can use positive reinforcement to motivate the child to continue learning. As a child begins to grasp the information the teacher could offer congratulations to the students [14]. Phrases such as, "you're doing a great job" and "I like how Joe answers the question right" can help spark the motivation. Teachers can also use extrinsic rewards to motivate students to do well in the learning environment. For example, when asking students to identify a shape or number, if they choose the correct answer the teacher can give the student a sticker. For many students receiving a sticker is a great source of happiness. It is also motivation to answer teacher 
questions correctly the next time. Many students experience burn out from receiving a great amount of knowledge at once. Motivation can help the students fight the urge to give up on learning.

A top priority for a teacher is protecting their students, whether it is from physical danger or any other type of danger [39]. For children stress can serve as serious threat. Young children are not developed enough to understand or cope with stress at this time in their lives. It has proven that motivation can help students in many ways, and can alleviate stress to a certain extent. Further research should examine specific motivational methods to relieve stress of students in a classroom environment.

\section{References}

[1] Humphrey, J. (2004). Childhood stress in contemporary society. New York, New York: Haworth Press.

[2] Shonkoff, J., Garner, A., Siegel, B., Dobbins, M., Earls, M., Wood, D. (2012). The Lifelong Effects of Early Childhood Adversity and Toxic Stress. American Academy of Pediatrics, 129(1), 232-246.

[3] Toxic Stress. (2015). Retrieved from http://developing child.harvard.edu/science/key-concepts/toxic-stress/

(Access Date: 15 April, 2017)

[4] Childhood Stress. (n.d.). Retrieved from http://kidshealth.org/en/parents/stress.html

[5] Is Your Child Too Busy? (n.d.). Retrieved from http://kidshealth.org/en/parents/child-too-busy.html (Access Date: 15 April, 2017)

[6] Fernandez, G. (2013, January 04). Importance of Family Time on Kids Mental Health and Adjustment to Life -. Retrieved from https://childdevelopmentinfo.com/ psychology/importance-of-family-time-on-kids-mentalhealth-and-adjustment-to-life/ (Access Date: 15 April, 2017)

[7] Wilson, S., \& Sato, A. (2013). Stress and Paediatric Obesity: What We Know and Where To Go. Stress Health Stress and Health, 91-102.

[8] Compas, B., Howell, D., Phares, V., Williams, R., \& Al, E. (1989). Parent and child stress and symptoms: An integrative analysis. Developmental Psychology, 25(4), 550-559.

[9] Thompson, R., \& Haskins, R. (2014). Early Stress Gets under the Skin: Promising Initiatives to Help Children Facing Chronic Adversity. The Future of Children, 1-6.

[10] Helping Kids Cope with Natural Disasters. (n.d.). Retrieved from https://www.nwf.org/Eco-Schools-USA/ Become-an-Eco-School/Hurricane-Sandy/Helping-KidsCope.aspx (Access Date: 15 April, 2017)
[11] Terada, Y. (2015, August 14). 17 Ways to Help Students With ADHD Concentrate. Retrieved from http://www.edutopia.org/discussion/17-ways-help-studentsadhd-fidget (Access Date: 15 April, 2017)

[12] Robert J. Coplan \& Kimberley A. Arbeau (2008) The Stresses of a "Brave New World": Shyness and School Adjustment in Kindergarten, Journal of Research in Childhood Education, 22:4, 377-389.

[13] Sharing and learning to share. (2016, May 2). Retrieved from http://raisingchildren.net.au/articles/sharing .html (Access Date: 15 April, 2017)

[14] Abigial Brown. Personal Communication

[15] Bernet, W. (2015). Children of High-Conflict Divorce Face Many Challenges. Psychriatric Times.

[16] United States Census Bureau. (2011). America's Families and Living Arrangements: 2011. Retrieved from http://www.census.gov/population/www/socdemo/hhfam/cps2011.html (Access Date: 15 April, 2017)

[17] Salek, E., \& Ginsburg, K. (2015, November 21). How Children Understand Death \& What You Should Say. Retrieved from https://www.healthychildren.org/English/ healthy-living/emotional-wellness/Building-Resilience/ Pages/How-Children-Understand-Death-What-YouShould-Say.aspx (Access Date: 15 April, 2017)

[18] Presta, R. (2013). The Parents Guide to New Siblings and Anxiety in Children. Retrieved from http://anxietyfree child.com/new-siblings-guide/ (Access Date: 15 April, 2017)

[19] Mayo Clinic. (2015). High blood pressure dangers: Hypertension's effects on the body. Retrieved from http://www.mayoclinic.org/diseases-conditions/high-bloodpressure/in-depth/high-blood-pressure/art-20045868

(Access Date: 15 April, 2017)

[20] Pietrangelo, A. (2014, April 8). The Effects of High Blood Pressure on the Body. Retrieved from http://www. healthline.com/health/high-blood-pressure-hypertension/ effect-on-body (Access Date: 15 April, 2017)

[21] Niolon, R. (2010, October 20). Dealing With Anger and Children | PsychPage. Retrieved from http://www.psy chpage.com/family/angry.html (Access Date: 15 April, 2017)

[22] Hawkins, J., Catalano, R., \& Miller, J. (1992). Risk and protective factors for alcohol and other drug problems in adolescence and early adulthood: Implications for substance abuse prevention. Psychological Bulletin, 112(1), 64-105.

[23] Crowe, A. (1998). Consequences of Youth and Substance Abuse. In Drug identification and testing in the juvenile justice system: Summary. Washington, DC: U.S. Dept. of Justice, Office of Justice Programs, Office of 
Juvenile Justice and Delinquency Prevention. Retrieved from http://www.ojjdp.gov/pubs/drugid/ration-03.html (Access Date: 15 April, 2017)

[24] Adam, T., \& Epel, E. (2007). Stress, eating and the reward system. Physiology \& Behavior, 449-458.

[25] Dallman, M. (2010). Stress-induced obesity and the emotional nervous system. Trends in Endocrinology \& Metabolism, 159-165.

[26] Balantekin, K., \& Roemmich, J. (2012). Children's coping after psychological stress. Choices among food, physical activity, and television. Appetite, 59, 298-304

[27] Krebs, N. F., Himes, J. H., Jacobson, D., Nicklas, T. A., Guilday, P., \& Styne, D. (2007). Assessment of child and adolescent overweight and obesity. Pediatrics 2007;12 0]:S193-S228

[28] Centers for Disease Control and Prevention. (2012). Childhood obesity facts. Retrieved from http://www.cdc. gov/HealthyYouth/obesity/facts.htm (Access Date: 15 April, 2017)

[29] Freedman, D. S., Zuguo, M., Srinivasan, S. R., Berenson, G. S., Dietz, W. H. (2007). Cardiovascular risk factors and excess adiposity among overweight children and adolescents: the Bogalusa Heart Study. Journal of Pediatrics 2007;150 (1):12-17.

[30] Li, C., Ford, E. S., Zhao, G., \& Mokdad, A. H. (2009). Prevalence of pre-diabetes and its association with clustering of cardiometabolic risk factors and hyperinsulinemia among US adolescents: NHANES 2005-2006.Diabetes Care 2009; 32:342-347.

[31] Guo, S. S. \& Chumlea, W. C. (1999). Tracking of body mass index in children in relation to overweight in adulthood. American Journal of Clinical Nutrition 1999; 70: S145-148.

[32] Office of the Surgeon General. (2010). The Surgeon General's Vision for a Healthy and Fit Nation. Rockville, MD, U.S. Department of Health and Human Services.

[33] Marcione, M. (2008). Fat Kids Have The Arteries of 45-Year-Olds, Study Shows. Retrieved from http://www. huffingtonpost.com/2008/11/11/fat-kids-have-the arterie _n_143115.html (Access Date: 15 April, 2017)

[34] Lavizzo-Mourey, R. (2004, March 26). Childhood Obesity-The Killer Threat Within. Lecture presented at Society of Behavioral Medicine Annual Meeting, Baltimore.

[35] Stress and Sleep. (n.d.). Retrieved from http://www.apa.org/news/press/releases/stress/2013/sleep.a spx (Access Date: 15 April, 2017)
[36] Schunk, D., Pintrich, P., \& Meece, J. (2014, April 23). Motivation. Retrieved from http://www.education.com/ reference/article/motivation/ (Access Date: 15 April, 2017)

[37] Ryan, R., \& Deci, E. (2000). Intrinsic and Extrinsic Motivations: Classic Definitions and New Directions. Contemporary Educational Psychology, 25, 54-67.

[38] Kirk, K. (2015). Motivating Students. Retrieved October 15, 2015, from http://serc.carleton.edu/NAGT Workshops/affective/motivation.html (Access Date: 15 April, 2017)

[39] Susan Huskey. Personal Communication.

[40] Regina Chapa. Personal Communication.

[41] Sabrina Vera. Personal Communication.

[42] Esther Ybarra. Personal Communication.

[43] Margaret Robinson/ Personal Communication.

[44] Sasson, D. (n.d.). Effective Goal Setting for Students. Retrieved from http://teaching.monster.com/benefits/ articles/9440-effective-goal-setting-for-students, (Access Date: 15 April, 2017)

[45] Reilly, E., Buskist, C., \& Gross, M. K. (2012, Summer). Movement in the Classroom: Boosting Brain Power, Fighting Obesity. Kappa Delta Pi Record, 48(2), 62-66.

[46] Hofferth, S., \& Sandberg, J. (2001). How American Children Spend Their Time. Journal of Marriage and Family, 63, 295-308.

[47] Sleep, Learning, and Memory. (n.d.). Retrieved from http://healthysleep.med.harvard.edu/healthy/matters/benefit s-of-sleep/learning-memory, (Access Date: 15 April, 2017) 